\title{
titelthema
}

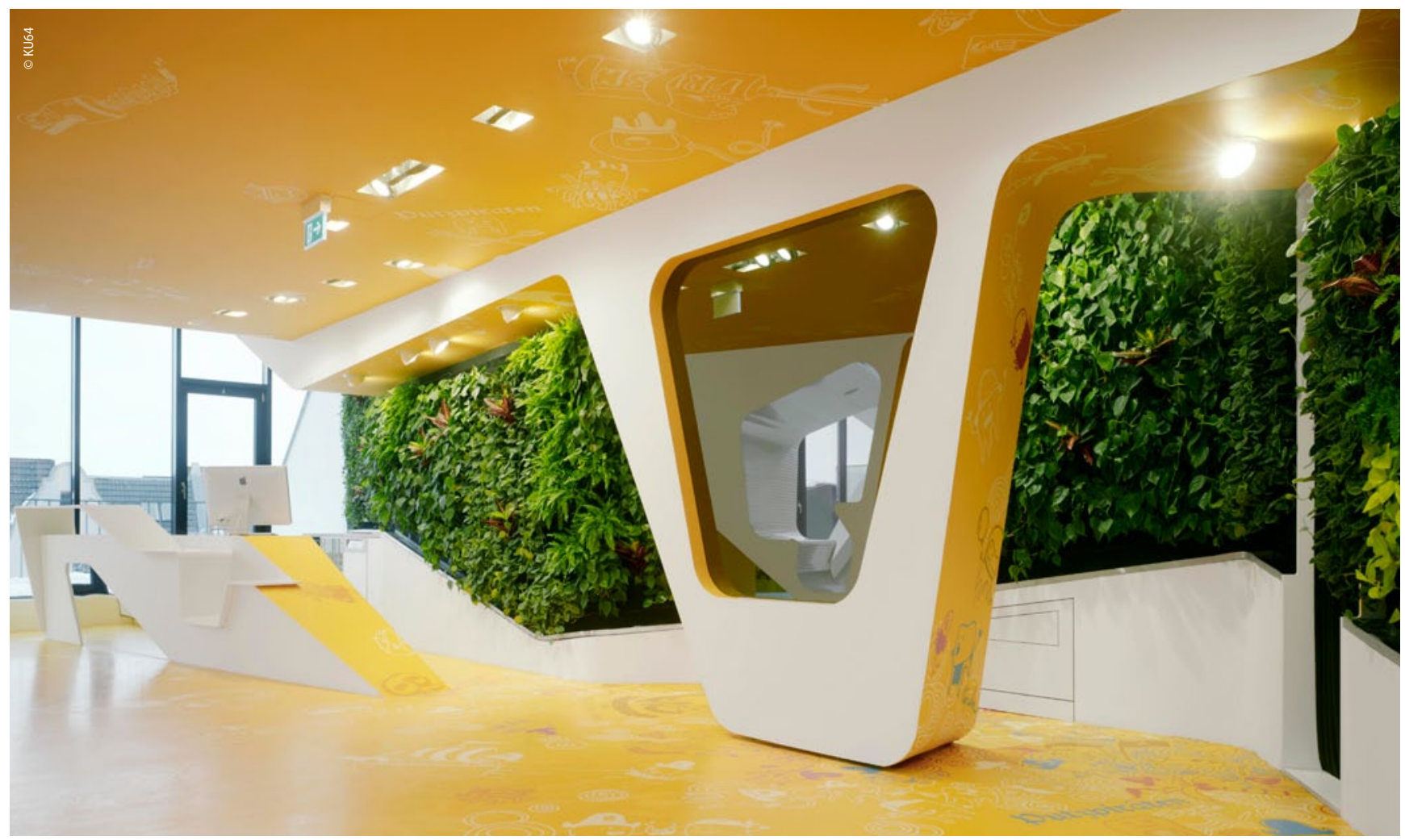

Pflanzen sind auch in Deutschlands größter Zahnarztpraxis KU64 integriert. Führungen für Kollegen ermöglicht der Praxisgründer auf Anfrage.

\section{Das sagt der Handel}

Tn der Regel gründet man eine Zahnarztpraxis nur ein- oder Zweimal, während Einrichtungsspezialisten über jahrelange Erfahrung und Know-how verfügen. Bei der Praxisplanung sind komplexe Zusammenhänge zu bedenken, die weit über die reine Raum- und Installationsplanung hinausgehen. Die Formgestaltung, die Auswahl der richtigen Materialien für Fußböden, Wände, Türen und Einrichtung sowie die Lichtplanung spielen wesentliche Rollen. Dabei sind die Unterstützung durch Experten und eine intensive Vorbereitung wesentlich, zum Beispiel in der Erlebniswelt Dentale Zukunft - einem modernen Praxisgestaltungszentrum für Zahnärzte in Münster. Besucher können dort Raumgestaltung, Ausstattung sowie Farb- und Lichtgestaltung live erleben. In einer „blackbox" kann zum Beispiel die unterschiedliche Wirkung des Lichts im Raum oder auf verschiedene Oberflächen bewertet werden. Ein Raum mit verschiebbaren Wänden bietet dem Besucher die Möglichkeit, die Raumplanung selbst auszuprobieren. Impulse und Ideen, wie der Beratungsablauf in der Praxis optimiert und der Patient als Kunde und nicht nur als Kranker behandelt werden können, stehen ebenso im Vordergrund.

Nadine Landes // NWD Gruppe, Nordwest Dental GmbH \& Co. KG, Münster

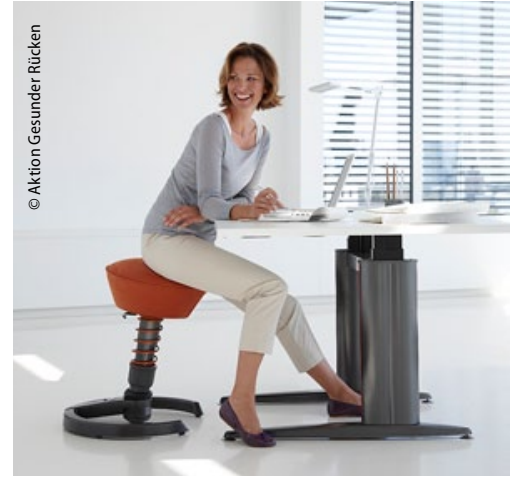

Durch seine weltweit einmalige dreidimensionale Beweglichkeit leistet dieser Bürostuhl einen aktiven Beitrag im Kampf gegen den Bewegungsmangel im Alltag.

"gerade im Bereich der Diagnostik und bei Operationen sehr gute Farbwiedergabewerte wichtig, um Feinheiten und Details gut zu erkennen", rät die Fördergemeinschaft Gutes Licht. Ausgewogene direkte und indirekte Lichtanteile bewirken bei den Patienten ein positives Gefühl und eine bessere Orientierung im Raum. Partiell eingesetztes farbiges Licht oder langsam ablaufende Farbwechsel können eine klinisch sterile Atmosphäre auflockern.

Moderne Leuchten mit „Light-emitting-diode“(LED)-Modulen sorgen durch hohe Energieeffizienz, eine Lebensdauer von bis zu 50.000 Betriebsstunden und niedrige Wartungskosten für einen ausgewogenen Kostenhaushalt. Räume mit viel Tageslicht brauchen nur eine unterstützende künstliche Beleuchtung in den vom Fenster abgewandten Bereichen. 